\title{
Breach of Psychological Contract and Compensation in Cases of Failure of Online Shopping Service
}

\author{
Mustafa Rashid Issa \\ Master of Law (LLM), University Utara Malaysia (UUM) \\ mustafarashiduum@yahoo.com
}

\section{Doi:10.5901/mjss.2015.v6n4p516}

\begin{abstract}
More and more researchers are now attracting and paying attention towards the notion of psychological contract in the relationship of marketing. This study suggests that the compensation of a psychological contract for online customers was associated to the class of individual value orientation of customers and breach of psychological contract. 139 respondents participated in the experiment that belongs to the Chinese university. Results of the study revealed that interaction effect of breach type on trust compensation and individual value orientation was highly significant. When breach is driven by ability, then, for cooperative individuals, compensation will be more useful for repairing trust, whereas more useful and effective in case of non-cooperative individuals when integrity is a sole reason of breach. Findings and results have great implications for improving service quality and making marketing strategies.
\end{abstract}

Keywords: Psychological Contract, Compensation, Breach, Online Customers, Trust

\section{Introduction}

The shared survey of Taobao and iResearch exposed that in 2007, the aggregate transaction value in China of online shopping touches the figure of 59.4 billion in comparison with 31.2 billion in 2006, boost up with $90.4 \%$. 55 million customers, among 210 million netizens, are doing online sale and purchase which indicates that prime buying/selling mode is 'online shopping' (iResearch \& Taobao, 2007-2008). 'How a pleasant relationship can be developed between online buyer and seller', and 'how to further improve the quality of online shopping services' received a great attention of researchers along with development and popularization of online shopping in China.

Apart from written contract, the contract which demonstrates the responsibilities and duties of the parties based on mutual agreement is known as psychological contract (Denise M Rousseau, 1989). Although this concept is derived from the subject of organizational behavior, presently several researchers argued that, between seller and buyer, there is existence psychological contract. Blancero and Ellram (1997) indicated in their research that in the situation of "employee-employer", empirical research had confirmed the psychological contract generated in friendly relationships, hence it also exists in the relationship of marketing. To the extent of relationship between external customers and company the psychological contract can be expanded as suggested by Roehling (1997). On the other side, Eddleston, Kidder, and Litzky (2002) suggested that a chain of psychological contract might be developed by the service agent along with customer. Thus, it is our believe that the agreement between seller and customer, obligation, desire and the mutual expectation will establish definite psychological contract during the process of online shopping, whose fulfillment will definitely affect the evaluation of customer about online vendor directly and influence its future buying pattern.

In organizational behavior field, the breach of psychological contract can be explained as the perception of employee regarding organizational failure to fulfill some obligations regarding psychological contract (Robinson \& Morrison, 1995). Results of past studies showed that the breach of psychological contract can lead towards a chain of adverse consequences like low work performance and higher turnover (Robinson, 1996; Robinson \& Morrison, 1995). In a virtual environment, the psychological contract between online customer and vendor becomes more important, which provides the link to the both parties, the violation or breach of which can lead towards bad consequences. Pavlou and Gefen (2005) confirmed that transaction intention and trust was related negatively to the breach of psychological contract of customer, whereas they have positive relation with perceived risk.

A second chance for successful transaction between seller and buyer is provided by compensation of psychological contract. The strength or weakness of a relationship between organization and employees depends on the way in which breach of psychological contract is deal, while mutual trust can be rebuild through appropriate 
compensation and it can enhance employees loyalty (Xiaoying \& Chunhua, 2004). In network context, if the issue is resolved successfully between online buyer and seller then customer will provide positive feedback about seller and, as well as, recommend it to other prospective buyers. Contrary to this, an unpleasant settlement of the issue may cause of loosing customer and it will spoil other prospective buyers which is a form of indirect loss of organization. More empirical and theoretical studies about psychological contract stress on the compensation lacks and different aspects of breach. This study discusses the compensation in psychological contract through a simulation experiment with the intention of enhancing of service quality through suitable compensation system, and good understanding of the relationship between seller and buyer.

\section{Background of the Study and Hypotheses}

\subsection{Trust}

It can be defined as the psychological circumstances in which an individual is willing to allow vulnerability, which is based on optimistic belief of one party towards behaviors or intentions of other party (D. M. Rousseau, Sitkin, \& Burt, 1998). The key properties of trust are vulnerability and risk. Ganesan (1994) proposed that there are two factors in which trust is composed of: (1) Reliability, that was partner expertise to accomplish task effectively, and (2) Integrity, the partner's goodwill to handle the right of a party if an unfavorable situation arise. Hence, trustor perceived both integrity and ability, which are affected by several subjective and objective factors, the trust level is not constant, and if someone will lose the trust it will disappear.

In the context of dynamic process of psychological contract, trust plays a significant role. At one side, trust can enhance the creation of psychological contract (Robinson, 1996), while on other side, adverse outcomes of the breach of psychological contract is break of trust (Robinson \& Morrison, 1995; Robinson \& Rousseau, 1994). Due to this reason, this study investigated the effect of compensation in psychological contract in accordance to the extent of trust repair.

Breach of psychological contract can be split up into two groups with respect to occurrence; integrity breach and ability breach. When the integrity breach belongs to breach of psychological contract, the seller has a right not agree to fulfill the psychological contract of a customer. On the other side, when the ability breach belongs to breach of psychological contract, selling is ready to fulfill the psychological contract of a customer but having no right. The literature shows that people focus on negative information while assessing the integrity of a person, and positive information while assessing the ability of a person (Murnighan, Kim, \& Metzger, 1993). When the buyer realizes the breach of psychological contract, the compensation behavior of a seller has two implications. First one is remediation, which is absolutely positive, and second one is responsibility of a seller in result of breach which is deemed as negative. Thus, for the integrity breach, the buyer focuses on the breach of comment of a seller, while for the ability breach; the buyer pays his/her attention on seller's sincerity to compensate for the fault.

$\mathrm{H}_{1}$ : The breach of psychological contract is associated with the difficulty degree of trust repair.

\subsection{Value Orientation of an Individual}

In psychological contract, individual element is a significant factor of dynamic process. D. M. Rousseau (1995) proposed that decoding and coding process of information is highly influenced by individual factors, since they affect psychological contract construction. Turnley and Feldman (1999) presented discrepancy model, which states that to moderate the negative responses of psychological contract, individual differences is considered as a significant factor. In assessment process, individual value orientation is one the individual factors which represent the individual's psychological tendency. It can be divided into four subcategories; relative interest, own interest, common interest, and including the interest of others. Messick and McClintock (1968) proposed, in accordance of aforesaid interests, that there are three kinds of value orientations; (1) Individual type: this type of people normally eager to maximize their own interest, (2) Competitive type: this type of people like to enhance relative interests, and (3) Cooperative type: this type of people have a target to maximize common interests. When ability breach happened, the distribution ratio varies while common interest remains unchanged. On the other hand, when there is occurrence of integrity breach, common interests become highly change while distribution ratio remains unchanged. Cooperative individuals, to the extent of ability factors, are deemed to me more sensitive, whereas, to the extent of integrity factors, competitive individuals are supposed to be more sensitive.

$\mathrm{H}_{2}$ : The category of the breach of psychological contract and orientation of individual value has an interaction effect on the difficulty degree of trust repair. 


\section{Research Method}

\subsection{Experimental Design}

Experimental design employed three individual value orientations (cooperative orientation, competitive orientation and individual orientation) and eleven rounds (design) and two breach categories of psychological contract (integrity breach and ability breach). This design is based on typical scenario of resource dilemma.

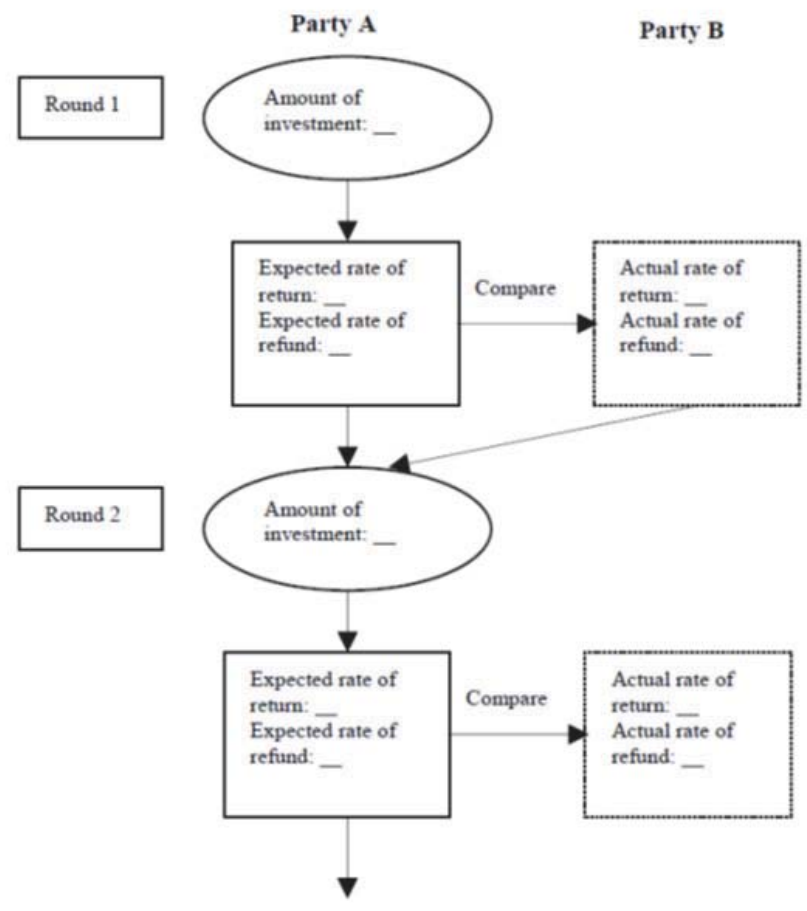

Figure 1: Experiment procedure

Party A \& B jointly participated in fund investment, and during this process the responsibility of Party A was just to provide capital, whose amount depends on the level of trust of Party A on Party B, whereas, responsibility of Party B was to manage capital. The rate of return is based on the ability of Party $B$.

When experiment started, it is required by the Party A to provide investment amount that he is intended to offer, along with his expected rate of refund and return. Afterward, he will adjust these three amounts after being informed by Party B about actual rate of refund and actual rate of return in the next round. And this procedure will continue till $11^{\text {th }}$ round was over (see Figure 1).

To control the integrity breach, the manipulation was used for the difference obtained from expected rate of refund and actual rate of refund. Similarly, to control the ability of psychological contract breach, manipulation was used for the difference obtained from expected rate of return and actual rate of return. In this study, the attention is paid to 3 rounds, including fifth round (before breach of psychological contract), sixth round (after the breach of psychological contract) and eleventh round (compensation of psychological contract).

\subsection{How we measure 'Trust'?}

This study measures the trust in two parts: one part is psychological trust measured by scale of trust; the other one is behavioral trust measured by investment amount in the experiment. After fifth, sixth and eleventh round, everyone was required to fill trust questionnaire so that the changes in his perceived trust can be examined on his partner.

The questionnaire was designed by following McAllister (1995) and Scheer, Kumar, and Steenkamp (2003) studies based on 7-item Likert scale (see Table 1) to measure trust, and it was modified according to the nature of our study. 
Table 1:

\begin{tabular}{|c|c|c|}
\hline \multicolumn{3}{|c|}{ Scale of Trust } \\
\hline Trust in Integrity & $\begin{array}{l}\text { TI1: In spite of circumstances become adverse, I am sure that my partner will always lend me } \\
\text { his hand. } \\
\text { TI2: At the time of decision-making, I am sure that my partner will consider my interest. } \\
\text { TI3: I trust on my partner that he'll consider the effect of his behavior and decisions on me. } \\
\text { TI4: I can rely on my partner's support in extreme crucial matters. }\end{array}$ & $\begin{array}{l}\text { (McAllister, } \\
1995)\end{array}$ \\
\hline Trust in Ability & $\begin{array}{l}\text { TA1: My partner has a capability to operate the investment } \\
\text { TA2: My partner possesses adequate information how to operate the investment. } \\
\text { TA3: My partner's investment skills are enough to get my confidence. }\end{array}$ & $\begin{array}{l}\text { (Scheer et al., } \\
2003)\end{array}$ \\
\hline
\end{tabular}

\subsection{How we measure Individual Value Orientation?}

The approach which was adopted to measure individual value orientation is 'triple matrix game'. It is efficient in retest reliability and internal consistency (De Dreu \& McCusker, 1997) (see Table 2).

In each case, as shown in Table 2, Choice 1 refers the maximization of own interest, while, Choice 2 symbolizes the maximization of the difference between own interest and, as well as, interest of partner, similarly, Choice 3 signifies the maximization of common interest. At the time of running test, participants were asked to choose one of them, while the sequence of these three choices was arranged randomly. Thus, individual value of orientation of the participants could be identified according to the choices they made.

Table 2:

\begin{tabular}{|l|c|c|c|c|c|c|}
\hline \multicolumn{2}{|c|}{ Triple Matrix Game } \\
\multirow{2}{*}{ Result } & \multicolumn{2}{|c|}{ Case\#1 } & \multicolumn{2}{c|}{ Case\#2 } & \multicolumn{2}{c|}{ Case\#3 } \\
\cline { 2 - 7 } & own score & other's score & own score & other's score & own score & other's score \\
\hline Choice\#1 & 50 & 20 & 50 & 15 & 60 & 30 \\
\hline Choice\#2 & 40 & 0 & 40 & 0 & 50 & 10 \\
\hline Choice\#3 & 40 & 40 & 40 & 40 & 50 & 50 \\
\hline
\end{tabular}

\subsection{Participants' Role}

A total of 139 students from undergraduate discipline became a part of experiment, whereas, males and females are 78 and 61 respectively. All participants were advised to cooperate in playing the role of either party (A or B) with another party after being selected randomly. But unfortunately, all participants played a role of Party A and computer program played a role of Party B.

\section{Research Results}

\subsection{Result of Individual Value Orientation}

By following the standard of De Dreu and McCusker (1997), participants were divided in one category with 7 consistent responses out of 12. To avoid complications, three non-cooperative types were incorporated (1) competitive type; (2) uncertain type, and (3) individual type. Results about participants' individual value orientation are presented in Table 3.

Table 3:

\begin{tabular}{|l|c|c|}
\hline \multicolumn{2}{|c|}{ Individual Value Orientation of Participants } \\
\hline Individual Value Orientation & $\begin{array}{c}\text { Category of Psychological } \\
\text { Contract Breach }\end{array}$ & Number of Participants \\
\hline \multirow{2}{*}{ Cooperative type } & Ability Breach & 40 \\
\cline { 2 - 3 } & Integrity Breach & 49 \\
\cline { 2 - 3 } & Sub Total & 89 \\
\hline Non-cooperative type & Ability Breach & 27 \\
\cline { 2 - 3 } & Integrity Breach & 23 \\
\cline { 2 - 3 } & Sub Total & 50 \\
\hline
\end{tabular}




\subsection{Effect of Psychological Contract Breach's Category on Trust Repair}

We define trust repair and investment repair according to the nature and need of our study. We defined trust repair as the difference of $11^{\text {th }}$ round (trust at third stage) and $6^{\text {th }}$ round (trust at second stage). Similarly, we defined investment repair as the difference between investment amounts of $11^{\text {th }}$ round (at third stage) and $6^{\text {th }}$ round (at second stage).

Values in Table 4 and Table 5 show significant amounts of all dependent variables between-groups effect with the category of psychological contract breach. For example, $f$ and $p$ values of total trust repair are 6.398 and 0.013 respectively, whereas $f$ and $p$ values of repair of trust in integrity are 5.629 and 0.019 respectively, similarly $f$ and $p$ values of repair of trust in ability are 34.240 and 0.000 respectively which support our hypothesis 1 .

Table 4:

\begin{tabular}{|l|c|c|c|c|}
\hline \multicolumn{5}{|c|}{ Analysis of Mean Values of Trust Repair } \\
\hline Categories & Total Trust Repair & Repair of Trust in Ability & Repair of Trust in Integrity & Investment Repair \\
\hline Integrity Breach & 0.5773 & 0.213 & 1.0729 & 1.0556 \\
\hline Ability Breach & 1.0043 & 1.3980 & 0.5784 & 1.7761 \\
\hline
\end{tabular}

Table 5:

\begin{tabular}{|l|c|c|c|c|c|c|}
\hline \multicolumn{7}{|c|}{ Analysis of Trust Repair Variance } \\
\hline Dependent Variable & Variation Sources & Sum of Squares & D.F & Mean Square & F-Values & Significance \\
\hline \multirow{2}{*}{ Total Trust_Repair } & Between & 6.328 & 1 & 6.328 & 6.398 & 0.013 \\
\cline { 2 - 7 } & Within & 135.502 & 137 & 0.989 & & \\
\cline { 2 - 7 } & Total & 141.830 & 138 & & & \\
\hline \multirow{2}{*}{ Repair of_Trust in Ability } & Between & 48.738 & 1 & 48.738 & 34.240 & 0.000 \\
\cline { 2 - 7 } & Within & 195.010 & 137 & 1.423 & & \\
\cline { 2 - 7 } & Total & 243.747 & 138 & & & \\
\hline \multirow{2}{*}{ Repair of _Trust in Integrity } & Between & 8.488 & 1 & 8.488 & 5.629 & 0.019 \\
\cline { 2 - 7 } & Within & 206.581 & 137 & 1.508 & & \\
\cline { 2 - 7 } & Total & 215.069 & 138 & & & \\
\hline \multirow{2}{*}{ Investment_Repair } & Between & 18.019 & 1 & 18.019 & 4.290 & 0.040 \\
\cline { 2 - 7 } & Within & 575.420 & 137 & 4.2 & & \\
\cline { 2 - 7 } & Total & 593.439 & 138 & & & \\
\hline
\end{tabular}

\subsection{Interaction effect of Category of psychological contract breach and individual value orientation on trust repair}

The effect of individual value orientation on trust repair was further examined. It can be observed from Table 6 that the effect of the category of psychological contract breach on total trust repair is insignificant. Conversely, the interaction effect of the category of psychological contract breach and individual value orientation ( $F=12.281, p=0.001)$ and main effect of individual value orientation ( $\mathrm{F}=3.901, \mathrm{p}=0.05)$ on total trust repair were significant.

Table 6:

\begin{tabular}{|l|c|c|c|c|c|}
\hline \multicolumn{5}{|c|}{ Effect of Interaction on Total Trusts Repair } \\
\hline Variation Sources & Sum of Squares & D.F & Mean Square & F-Values & Significance \\
\hline Individual Value_Orientation & 3.499 & 1 & 3.499 & 3.910 & 0.05 \\
\hline Category of Psychological_Contract Breach & 2.699 & 1 & 2.699 & 3.015 & 0.085 \\
\hline $\begin{array}{l}\text { Individual Value_Orientation x Category of } \\
\text { Psychological_Contract Breach }\end{array}$ & 10.992 & 1 & 10.992 & 12.281 & 0.001 \\
\hline Residuals & 120.826 & 135 & 0.895 & & \\
\hline
\end{tabular}

Subsequently, in same way we examined the category of psychological contract breach and interaction effect of individual value orientation on the repair of trust in integrity and as well as ability. Results reveal the existence of breach 
type and interaction effect of individual value orientation on repair of trust in integrity ( $f=4.559, p=0.035)$ and repair of trust in ability $(f=9.751, p=0.002)$.

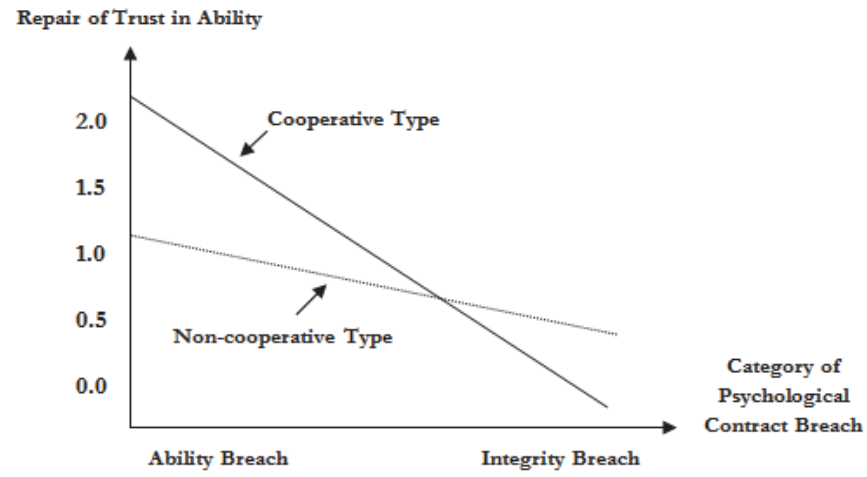

Figure 2: Repair of Trust in Ability

As shown in Figure 2, repair degree of trust in ability of non-cooperative individuals is lower than that of cooperative individuals when ability breach of psychological contract takes place. Similarly, the repair degree of trust in ability of cooperative individuals is somewhat lower than that of non-cooperative individuals when the integrity breach of psychological contract takes place. However this difference is insignificant.

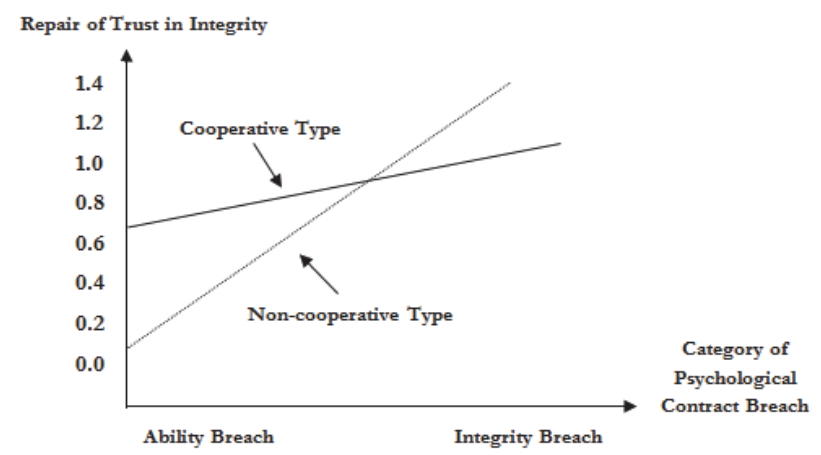

Figure 3: Repair of Trust in Integrity

Likewise, it is obvious in Figure 3 that the repair degree of trust in integrity of non-cooperative individuals is lower than that of cooperative individuals when ability breach of psychological contact takes place. Simultaneously, it is also clear that the repair degree of trust in integrity of cooperative individuals is lower than that of non-cooperative individuals. So we can support our hypothesis 2 on the basis of aforesaid results and discussion.

\section{Conclusion and Implication}

On the basis of obtained results we can conclude that significant effect imposed by the category of breach of psychological contract on attitude and repair of trust behavior. In a situation of ability breach of psychological contract, the average values of both investment repair and total trust repair are higher than those in a scenario of integrity breach, which implies that effect of compensation is influenced by category of psychological contract breach. After making some compensation by the seller, customers are more expected to recover their trust only if the breach occurs due to ability factors. Contrary to that, customers cannot regain their level of trust even offering several compensation measures by the seller if the breach occurs due to integrity factors. Hence, it can be concluded that seller should provide a chance to customers to solve problems, try to get better its own ability, try to establish its honest image, and as well as provide "winwin" principle services.

In the meantime, category of psychological contract breach and individual value orientation put interaction effect on trust repair. The non-cooperative buyers are more sophisticated to integrity factors, whereas, the cooperative buyers are more sophisticated to ability factors. Consequently, seller should consider individual value orientation of the buyer in 
order to get better results while compensating a psychological contract of a customer. Seller should represent his ability improvement efforts, while dealing with cooperative customers, to convince and inspire him/her and ensure him/her that he/she will get more better services in future, for example selection of more secure delivery channel or getting more reliable sources of goods. On the other hand, seller should own his mistake timely and appropriately while dealing with non-cooperative customers, give sincere and genuine excuse, and comply on refund policies or return faulty goods by confirming that buyer appropriately feel his sincerity and generosity. Finally, websites should introduce interesting and small programs in a convenient way to assess the buyers' individual value orientation.

\section{References}

Blancero, D., \& Ellram, L. (1997). Strategic supplier partnering: A psychological contract perspective. International Journal of Physical Distribution \& Logistics Management, 27(9/10), 616-629.

De Dreu, C. K., \& McCusker, C. (1997). Gain-loss frames and cooperation in two-person social dilemmas: A transformational analysis. Journal of personality and social psychology, 72(5), 1093.

Eddleston, K. A., Kidder, D. L., \& Litzky, B. E. (2002). Who's the boss? Contending with competing expectations from customers and management. The Academy of Management Executive, 16(4), 85-95.

Ganesan, S. (1994). Determinants of long-term orientation in buyer-seller relationships. the Journal of Marketing, 1-19.

iResearch, \& Taobao. (2007-2008). Report of Online Shopping Development of China.

McAllister, D. J. (1995). Affect-and cognition-based trust as foundations for interpersonal cooperation in organizations. Academy of management journal, 38(1), 24-59.

Messick, D. M., \& McClintock, C. G. (1968). Motivational bases of choice in experimental games. Journal of experimental social psychology, 4(1), 1-25.

Murnighan, J. K., Kim, J. W., \& Metzger, A. R. (1993). The volunteer dilemma. Administrative science quarterly, 515-538.

Pavlou, P. A., \& Gefen, D. (2005). Psychological contract violation in online marketplaces: Antecedents, consequences, and moderating role. Information systems research, 16(4), 372-399.

Robinson, S. L. (1996). Trust and breach of the psychological contract. Administrative science quarterly, 574-599.

Robinson, S. L., \& Morrison, E. W. (1995). Psychological contracts and OCB: The effect of unfulfilled obligations on civic virtue behavior. Journal of organizational behavior, 16(3), 289-298.

Robinson, S. L., \& Rousseau, D. M. (1994). Violating the psychological contract: Not the exception but the norm. Journal of organizational behavior, 15(3), 245-259.

Roehling, M. V. (1997). The origins and early development of the psychological contract construct. Journal of Management History, 3(2), 204-217.

Rousseau, D. M. (1989). Psychological and implied contracts in organizations. Employee responsibilities and rights journal, 2(2), 121139.

Rousseau, D. M. (1995). Psychological Contracts in Organizations: Understanding Written and Unwritten Agreements. Thousand Oaks: Sage Publications, 285-298.

Rousseau, D. M., Sitkin, S. B., \& Burt, R. S. (1998). Introduction to Special Topic Forum: Not So Different After All: A Cross-Discipline View of Trust. Academy of Management Review, 23(3), 393-404.

Scheer, L. K., Kumar, N., \& Steenkamp, J.-B. E. (2003). Reactions to perceived inequity in US and Dutch interorganizational relationships. Academy of management journal, 46(3), 303-316.

Turnley, W. H., \& Feldman, D. C. (1999). A discrepancy model of psychological contract violations. Human resource management review, 9(3), 367-386.

Xiaoying, L., \& Chunhua, C. (2004). Psychological Contract Compensation. Science and Technology Management Research, 6, 111113. 